\title{
O PROCESSO DE ENSINO-APRENDIZAGEM E AS REDES SOCIAIS: A NECESSIDADE DE UMA EDUCAÇÃO DIGITAL
}

\author{
The Teaching Learning Process and Social Networks: The Need of Digital Education
}

\author{
Ana Catarina Sena de Paiva* \\ Antognioni Pereira de Melo** \\ Raquel Machado Gomes Marques***
}

\begin{abstract}
Resumo: O presente artigo tem por objetivo discutir sobre a relação entre o processo de ensinoaprendizagem e as redes sociais na internet a partir da análise dos dados levantados por meio da técnica de pesquisa questionário, direcionada a diversos profissionais educadores de diferentes ocupações e segmentos, de instituições públicas ou privadas do Distrito Federal. Por meio dessa análise, da revisão bibliográfica e, principalmente, do resgate da BNCC como referência oficial que integra as mudanças sociais em desenvolvimento e apresenta as competências e habilidades que o ensino básico deve desenvolver nos estudantes, o artigo visa compreender a realidade sobre os projetos de educação digital nas instituições de ensino e averiguar se tais projetos já estão sendo realizados de alguma forma por essas instituições. Ressaltamos a correlação entre educação e cultura, principalmente no que tange à era digital, que traz consigo demandas à prática educacional. Essas demandas são encaradas de diferentes formas pelos profissionais questionados, tanto com aspectos negativos quanto positivos do uso de tecnologias e, principalmente, das redes sociais na internet.
\end{abstract}

Palavras-chave: Cultura digital. Educação Digital. Formação de Educadores.

Abstract: This article aims to discuss the relationship between the teaching-learning process and social networks on the internet from the analysis of the data collected through the

\footnotetext{
* Possui Licenciatura em Pedagogia pela Universidade de Brasília (2017). Especialização em Orientação Educacional, Coordenação Pedagógica e Psicopedagogia (2018). Atualmente cursa Mestrado em Educação pela Universidade Católica de Brasília nos seguintes temas: inclusão escolar, educação integral e formação continuada de professores. ORCID: https://orcid.org/0000-0003-4665-7289. E-mail: catarinasena1996@gmail.com.

** Possui Licenciatura em Computação pela Universidade de Brasília (2011). Especialização em Gestão de TI pela IMP e Mestrado em Educação Social e Intervenção Comunitária pelo Instituto Politécnico de Santarém, em Portugal. Atualmente cursa Doutorado em Educação na Universidade Católica de Brasília e é Professor de informática efetivo do Instituto Federal de Brasília, atuando, principalmente, nos seguintes temas: educação social, informática aplicada à educação e Ensino a distância. ORCID: https://orcid.org/0000-0002-1257-9633. Email: melovis@gmail.com.

*** Possui Licenciatura em Pedagogia pela Faculdade de Teologia Hokemah (2017). Especialização em Docência do Ensino Superior. É professora visitante de Pedagogia no Instituto Ícone de Consultoria, Cursos e Educação e professora de Teologia e Pedagogia no Instituto Capacita de Brasília. É pesquisadora da Educação na PósModernidade, especialmente no campo da ética. Mestranda em Educação pela Universidade Católica de Brasília. ORCID: https://orcid.org/0000-0003-2912-6822. E-mail: raquel.imaa@gmail.com.
} 
questionnaire research technique, aimed at several educating professionals from different occupations and segments, from public or private institutions in the Federal District. Through this analysis, the bibliographic review and, mainly, the rescue of BNCC as an official reference that integrates social changes in development and presents the skills and abilities that basic education should develop in students, the article aims to understand the reality about the projects of digital education in educational institutions and find out if such projects are already being carried out in any way by these institutions. We emphasize the correlation between education and culture, especially with regard to the digital age, which brings demands to educational practice. These demands are faced in different ways by the professionals questioned, both with negative and positive aspects of the use of technologies and, mainly, of social networks on the internet.

Keywords: Digital culture. Digital education. Educator Training

\title{
1 Introdução
}

A cultura digital transformou as relações no mundo de maneira ampla e sistêmica, fazendo-nos adentrar em uma nova época: a era digital. Sobre essa realidade, Lucia Santaella (2003, p. 70, 71) já dizia:

\begin{abstract}
O aspecto mais espetacular da era digital está no poder dos dígitos para tratar toda informação, som, imagem, vídeo, texto, programas informáticos, com a mesma linguagem universal, uma espécie de esperanto das máquinas. Graças à digitalização e compressão dos dados, todo e qualquer tipo de signo pode ser recebido, estocado, tratado e difundido, via computador. Aliada à telecomunicação, a informática permite que esses dados cruzem oceanos, continentes, hemisférios, conectando potencialmente qualquer ser humano no globo numa mesma rede gigantesca de transmissão e acesso que vem sendo chamada de ciberespaço.
\end{abstract}

A escola, enquanto instituição social, não está isolada desse novo paradigma e se vê frente à necessidade de se adequar ao seu contexto a fim de que possa, verdadeiramente, auxiliar na construção do conhecimento desse novo sujeito do século XXI. Esse sujeito carece de um ensino que considere sua integralidade e gere-lhe interesse, bem como de uma prática reflexiva que delineie experiências significativas.

A Base Nacional Comum Curricular (BNCC) é a referência oficial que integra as mudanças sociais em desenvolvimento. Nesse documento, constam as competências e as habilidades que o ensino básico deve desenvolver nos estudantes, tal como a leitura crítica de informações de revistas, jornais, internet e redes sociais. Além disso, a BNCC também prevê a postura crítica e ética dos estudantes brasileiros na produção e no compartilhamento de comentários $^{1}$, opiniões, "memes"2 e outros elementos digitais (BRASIL, 2018).

Diante do exposto, é fundamental que investiguemos se há aplicação prática daquilo que a BNCC prevê ou se ainda se detecta uma carência nas escolas com respeito à educação digital.

\footnotetext{
${ }^{1}$ Umas das atuais funcionalidades tecnológicas é a possibilidade de compartilhamento de conteúdos com outros contatos ou usuários de serviços online. Essa ação permite rápida e ampla transmissão e disseminação de informações de diversos tipos, como notícias, imagens, textos, vídeos e links.

2 "Meme" é caracterizado como uma ideia ou um conceito geralmente apresentado em forma de uma figura que expressa um sentido ou uma reação, aplicada a um certo contexto. Também pode ser um vídeo ou uma frase. Cada "meme" é aplicado dentro de uma situação em que há um certo padrão de significado.
} 
Também precisamos refletir sobre os desafios consideráveis que essa cultura digital demanda dos educadores, já que a mídia digital -internet, telefonia móvel, jogos de computador, televisão interativa - é, hoje, um aspecto indispensável na vida das crianças e dos jovens.

Para este estudo, a respeito do processo de ensino-aprendizagem envolvendo cultura digital, redes sociais e necessidade de uma educação digital, levantamos dados por meio da técnica de pesquisa questionário. As perguntas intentaram delinear o perfil dos profissionais da educação participantes e avaliar suas opiniões a respeito do impacto das redes sociais nas relações construídas dentro do ambiente escolar no processo educativo - seja entre os educandos, seja entre professores e alunos -, bem como detectar se existem projetos de educação digital no contexto escolar.

Assim, a presente investigação tem como problema de pesquisa conhecer a realidade das instituições escolares no tocante aos seus projetos de educação digital, bem como a visão dos profissionais de ensino sobre a influência das redes sociais na formação dos estudantes de educação básica. Por consequência, essa apuração trará luz ao preparo da comunidade escolar frente às demandas desse novo cenário, de acordo com os pressupostos da BNCC.

Com respeito à metodologia de pesquisa utilizada, a coleta de dados foi realizada a partir da utilização da tecnologia Google Forms. Com o objetivo de atingir mais educadores da região do Distrito Federal, o link de acesso ao questionário foi enviado por meio da rede social WhatsApp em diferentes grupos. Os participantes recebiam a pesquisa e podiam realizar seu compartilhamento com outros educadores da sua comunidade escolar. $\mathrm{O}$ prazo estipulado para coleta dos dados foi de sete dias úteis, estendidos para mais sete dias. Ao final, os educadores tiveram quatorze dias úteis para enviarem suas respostas.

O formulário foi divulgado contendo nove questões, a saber: 1. nome; 2. idade; 3. ocupação (professor, orientador educacional, coordenador pedagógico, educador em fase de estágio e diretor pedagógico); 4. Segmento (Educação infantil, Ensino Fundamental Anos Iniciais ou Finais, Ensino Médio, Técnico ou Superior, EJA - Ensino Fundamental, EJA Ensino Médio e Outros); 5. Tipo de Instituição (pública ou privada) e, a partir de então, as perguntas-núcleo da pesquisa: 6. Na sua opinião e análise, é possível estabelecer uma relação entre os conflitos escolares dos educandos e as redes sociais? 7. Quais são os desafios advindos do mau uso das redes sociais que você enfrenta como educador? 8. Em sua escola, há algum projeto de educação digital? Se sim, qual? 9. Você acredita que as redes sociais poderiam ser ferramentas para o desenvolvimento dos alunos? Justifique. Ao findar o prazo de retorno das respostas, contabilizamos 74 questionários respondidos, de forma que 3\% dessa totalidade ficaram sem resposta para algumas das questões discursivas.

Por fim, devido à natureza da proposta, a análise e interpretação dos dados foram realizadas a partir de estudos de método qualitativo, a fim de se obter melhor entendimento da realidade, promover discussões, desenvolvimento de novas teorias ou novas abordagens para o tema.

\section{Referencial teórico}

Algumas definições são importantes para a presente pesquisa, tais como: o que é educação digital? E educação midiática? O que são redes sociais? Vale ressaltar que identificamos, nas literaturas e nos documentos consultados, expressões como "educação digital", "letramento digital", "educação midiática" e "letramento midiático", as quais aparentam ter o mesmo significado. No entanto, neste artigo, consideramos algumas 
especificidades da educação digital e da educação midiática, mesmo que suas definições, por vezes, pareçam confundir-se.

Primeiramente, destacamos que esses termos são, frequentemente, mal definidos. David Buckingham (2010, p. 48) considera ser deficiente uma definição essencialmente funcional que destaca somente as "capacidades básicas necessárias para a realização de certas operações". Sobre a educação digital, o autor assevera que esta não é apenas um "know-how técnico mais fácil de ser adquirido e as habilidades que, talvez, tornam-se obsoletas muito mais rápido”.

A educação digital não diz respeito, simplesmente, a aprender a usar o computador ou, até mesmo, os navegadores e mecanismos de busca. Devemos considerar os usos culturais dos meios digitais, bem como os desafios e as possibilidades que surgem a partir deles. Se considerarmos a educação, o domínio das possibilidades das ferramentas e os meios digitais precisam expandir-se para a formação e atividade dos docentes. Questões éticas e de cidadania, por conseguinte, podem ser ressaltadas, a fim de que desenvolvamos o respeito e a dignidade humana (FIDALGO, 2019).

Quanto à educação midiática, o termo parece apresentar-se de maneira mais específica, de forma a enfatizar tanto a escrita quanto a leitura de mídias; ou seja, uma espécie de letramento. A compreensão do processo desse letramento é ainda mais crítica, pois considera a emancipação do sujeito, as atividades políticas e as transformações sociais. Buckingham (2010, p. 52) aponta:

\footnotetext{
No contexto da educação midiática, o objetivo não é inicialmente o de desenvolver habilidades técnicas, nem promover a autoexpressão, mas estimular uma compreensão mais sistemática de como funciona a mídia e daí promover formas mais reflexivas de usá-la.
}

$\mathrm{Na}$ educação midiática, assevera-se a necessidade de formar o sujeito para refletir e criticar a confiabilidade de informações, bem como para analisar as notícias em diferentes fontes e mídias (BRASIL, 2018). Objetiva-se, assim, uma formação para tirar o melhor proveito do ambiente midiático, de maneira que o sujeito participe ativamente de seu contexto como cidadão e ser reflexivo.

Sobre o assunto, Normand Landry e Joelle Basque (2019, p. 3) afirmam:

a educação para as mídias se concentra na análise, na compreensão e na reflexão crítica de mensagens midiáticas e trata de contextos sociais, políticos, econômicos, tecnológicos e culturais nos quais tais mensagens são produzidas, difundidas e recebidas.

O conceito de "Redes sociais" é muito divulgado e discutido nos dias atuais. Nesses termos, Recuero (2009) considera a união de dois fatores: os atores e as suas conexões. Os atores podem ser usuários, instituições ou grupos. As conexões são as devidas interações entre esses atores, também chamadas de "laços sociais". Interessante perceber que a essência desse conceito não está vinculada ao mundo digital, tal como o percebemos hoje; assim, Turchi (2019) esclarece essa definição e apresenta a diferença entre rede social, mídia social e sites de relacionamento: 
Em termos conceituais ainda há certa confusão entre mídias sociais e redes sociais. Na verdade, as redes sociais nada mais são do que grupos de pessoas com interesses comuns, que não necessariamente dependem da Internet para existir. Grupos que se reúnem para conversar sobre os mais diversos temas - o que inclui falar sobre marcas, produtos, serviços, empresas etc. -, jogar ou simplesmente bater papo. O que mudou é que com a evolução da Web 2.0, isso se reproduziu no ambiente virtual e cresceu de forma exponencial. O surgimento dos sites de relacionamento, que passaram a ser chamados de "redes sociais", como Facebook, LinkedIn, Instagram, Snapchat, Google+, Twitter, só para citar alguns mais conhecidos, permitiram reunir na web várias comunidades (redes) com regras próprias, possibilitando a seus integrantes interagir de várias formas e trocar informações de interesse comum. (TURCHI, 2019, p. 139).

De acordo com o exposto, a rede social, tal como é expressa atualmente, seria, na verdade, uma rede social com seus atores e laços sociais tendo a internet como espaço de atuação; dessa forma, esse termo deveria ser mais propriamente referido como redes sociais na internet, tal como apresenta Recuero (2009).

\section{Análise dos dados}

\subsection{Perfil dos participantes}

As idades dos participantes da pesquisa variam entre vinte a 56 anos. Todos eles são profissionais do ensino, com diferentes níveis de ocupação, atuantes em diferentes segmentos e em instituições públicas ou privadas do Distrito Federal.

Conforme o gráfico abaixo, tivemos a maioria dos respondentes ocupando o cargo de Professor ou Professora - 84,3\% da amostra. Esse resultado, aliado também aos outros profissionais de ensino, demonstrou-se de grande valia para a pesquisa, visto que os/as docentes, devido à sua proximidade com os alunos e à sua vivência na sala de aula, podem ter maior compreensão sobre as atitudes e reações dos estudantes com relação aos projetos e programas pedagógicos desenvolvidos na escola.

Figura 1 - Ocupação profissional
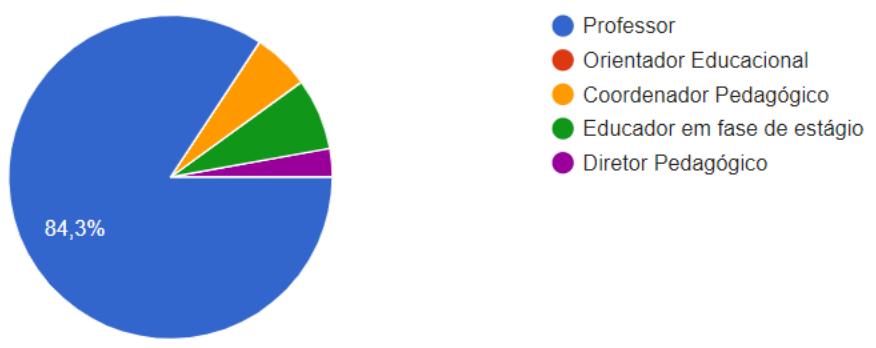

Fonte: Gráfico elaborado automaticamente pelo Google Forms a partir das respostas ao questionário.

Em termos de segmento de atuação, tivemos números próximos com relação a profissionais atuantes no Ensino Médio e Ensino Fundamental (Anos iniciais), e também números similares com relação aos profissionais atuantes na Educação Infantil e Ensino Fundamental (Anos Finais). Destaca-se, nesse resultado, uma pequena parcela de profissionais atuantes nos segmentos de nível técnico e superior. Como o foco da pesquisa se deu na 
formação da educação básica, esse também foi um resultado muito positivo para a investigação, visto que mais de $90 \%$ dos profissionais respondentes atuam nessa etapa. Contudo, salientamos que não tivemos a participação de profissionais da EJA - Ensino Médio. Tal composição pode ser observada abaixo:

Figura 2 - Segmento de atuação

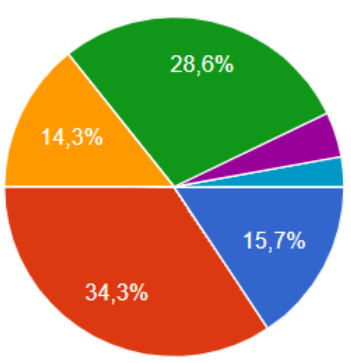

Educação Infantil

Ensino Fundamental Anos Iniciais

Ensino Fundamental Anos Finais

Ensino Médio

Técnico ou Superior

Educação de Jovens e Adultos-

Ensino Fundamental

Educação de Jovens e Adultos-

Ensino Médio

Fonte: Gráfico elaborado automaticamente pelo Google Forms a partir das respostas ao questionário.

Do total de respondentes, $68,1 \%$ atuam em rede privada e $31,9 \%$, na rede pública. Não percebemos mudanças significativas com relação às respostas no quesito instituição privada ou pública. Seguimos, então, para a análise das respostas dos participantes às perguntas-núcleos da pesquisa.

3.2 Análise das respostas às questões discursivas

3.2.1 Na sua opinião e análise, é possível estabelecer uma relação entre os conflitos escolares dos educandos e as redes sociais?

Essa pergunta teve como intuito detectar os possíveis maus usos das redes sociais e de outros meios digitais percebidos pelos educadores na relação entre educandos. Se estamos refletindo sobre o processo de ensino-aprendizagem, certamente não podemos desconsiderar a relação entre os próprios sujeitos educativos, sejam eles educadores ou educandos, e, até mesmo, os conflitos que ocorrem nessas relações.

As respostas obtidas a essa pergunta estão demonstradas no gráfico abaixo:

Figura 3 - Possível relação entre os conflitos escolares dos educandos e as redes sociais.

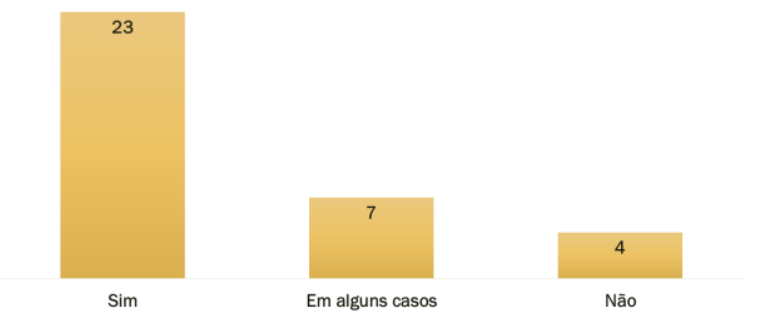

Fonte: Elaboração nossa. 
Os profissionais da amostra tiveram a possibilidade de realizarem seus próprios comentários na questão. No que diz respeito à categoria "Em alguns casos", identificamos comentários de que as redes sociais trazem novas formas de nos relacionarmos e, também, muitos desafios. O desinteresse dos alunos e o fato de as relações sociais serem, por vezes, restritas ao contexto das redes sociais foram aspectos destacados.

Na categoria "Sim", um respondente pontuou:

[...] é importante lembrarmos que conflitos escolares existem muito antes do surgimento das redes sociais. De todo modo, pensando no contexto atual, os(as) educadores(as) têm desafios a serem enfrentados em razão da atmosfera violenta criada em nossa sociedade por meio das redes sociais, que talvez potencializam a agressividade existente nas pessoas fora do ambiente virtual. Esse debate é amplo e exige, de nós, considerações acerca das mais diversas áreas do conhecimento.

Ainda nessa categoria, outro respondente salientou:

Acredito que, com um estudo e acompanhamento, as redes sociais ajudam muito a vida dos educandos. Hoje, todos estão envolvidos de alguma forma nas mídias digitais, o que nos leva a entender que o mundo precisa acompanhar a tecnologia; a escola não pode ser diferente.

Nas falas dos profissionais de educação questionados, evidenciou-se que não é a rede social que somatiza os conflitos na escola, e, sim, a falta de consciência, a incorreta interpretação de texto e a falta de respeito para com o próximo, ou seja, a utilização errônea das tecnologias. Assim, para esse grupo, as redes sociais tornam-se "um extra" nos conflitos escolares.

Na categoria "Não", os respondentes não explicam ou esclarecem o motivo de suas discordâncias. Apenas sugerem que, a princípio, não haveria relação entre a rede social e os conflitos escolares. Imagina-se que esses profissionais talvez não tenham vivido alguma experiência nesse sentido ou não perceberam alguma correlação entre uma possível indisciplina dos estudantes e o uso das redes sociais.

\subsubsection{Quais são os desafios advindos do mau uso das redes sociais que você enfrenta como educador?}

De acordo com Giane da S. F. Yasawa e Eliacir Neves França (2013), a falta de maturidade dos estudantes ao postar conteúdos nas redes suscita discórdias no contexto escolar. As redes sociais trazem, portanto, tanto avanços quanto dilemas éticos. Dentre esses dilemas, Paulo Cesar Masiero (2000) cita: o uso privilegiado de dados confidenciais ou a divulgação de dados impróprios pela Internet; o acesso não autorizado a sistemas computacionais; a discussão acerca do direito de propriedade de softwares; as questões relativas ao direito autoral na rede, entre outros.

Na figura a seguir, ilustramos os principais tópicos apresentados pelos profissionais da educação quando questionados a respeito dos desafios enfrentados pelo educador frente ao mau uso das redes sociais. O tamanho dos círculos é correlacionado à frequência com que cada tópico foi levantado. 
Figura 4 - Desafios advindos do mau uso das redes sociais.

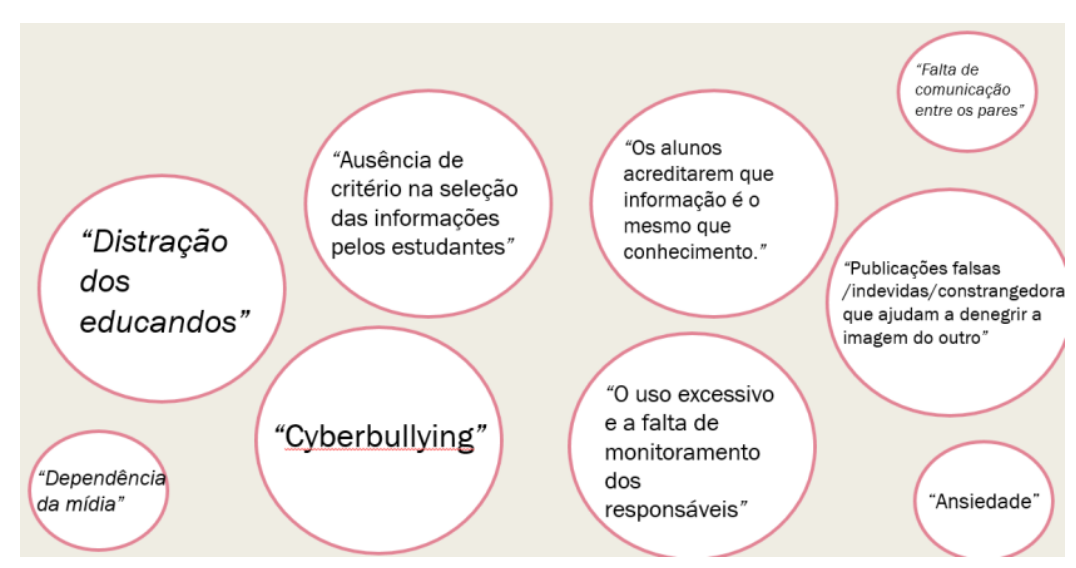

Fonte: Elaboração nossa

A categoria "Distração dos Educandos" foi uma das mais citadas pelos profissionais. O uso das redes sociais em sala de aula é cada vez mais frequente e, por vezes, incomoda os educadores. Um professor expôs a dificuldade em:

lidar com a falta de concentração dos alunos e a falta de paciência deles (sempre querem resultados imediatos como eles têm nos celulares). Conseguir identificar bullying virtual, relacionamentos abusivos ou não saudáveis que os alunos têm nas redes sociais são os desafios advindos do mau uso das redes sociais que enfrento diariamente.

Diante da extensão do uso de redes sociais no dia a dia dos estudantes, a sua proibição segue o caminho oposto ao da aprendizagem, pois, dessa forma, os educandos não são instigados a aprenderem a usar de forma responsável os aparelhos eletrônicos na escola e na vida, mas são apenas "impedidos” de utilizá-los, sem nenhum diálogo envolvido. Assevera-se que as redes sociais, quando bem empregadas, podem ser consideradas uma forma de aprendizagem colaborativa.

Hugo Funks et al. (2006, p. 369) ressaltam essa aprendizagem colaborativa que pode ocorrer a partir dos espaços virtuais:

$\mathrm{Na}$ aprendizagem colaborativa, o aprendiz é responsável pela sua própria aprendizagem e pela aprendizagem dos outros membros do grupo. Os aprendizes constroem conhecimento através da reflexão a partir da discussão em grupo. A troca ativa de informações instiga o interesse e o pensamento crítico, possibilitando aos aprendizes alcançarem melhores resultados do que quando estudam individualmente.

A partir dessa compreensão, quando o assunto é a dispersão dos alunos, por que não usar as redes sociais como instrumento de aprendizagem? As crianças e os jovens de hoje, com o advento das redes sociais, não se sentem motivados a partir de um ensino tradicional. Os meios online podem complementar o processo de ensino-aprendizagem e transformar as distrações em ferramentas. 
Outros aspectos citados pelos profissionais de educação no levantamento realizado englobam uma categoria maior do uso inconsciente das redes sociais. Os educadores salientaram a "Ausência de critério na seleção das informações pelos estudantes"; "Os alunos acreditarem que informação é o mesmo que conhecimento"; "O uso excessivo e a falta de monitoramento dos responsáveis"; "Dependência da mídia"; "Falta de comunicação entre os pares"; e "Ansiedade".

A criticidade quanto à confiabilidade de informações e a sites específicos são elementos desenvolvidos pela educação midiática prevista na BNCC. Assim, tornou-se um papel da escola e dos educadores impulsionar os alunos à reflexão crítica e ao comprometimento em entender de onde vem determinada matéria ou publicação, bem como se a base de dados é confiável ou não, a fim de evitar a disseminação de fake news, por exemplo.

O "uso excessivo", a "dependência da mídia" e a "falta de comunicação entre os pares" são descritos, segundo C. N. Abreu et al. (2008), de diversas formas, tais como "vício da Internet", "uso patológico", "uso compulsivo" e "dependência".

Aqui, vamos caracterizá-los como "dependência comportamental" (CARBONELL et al. apud FORTIM; ARAÚJO, 2013). A parceria escola-família precisa estar bem consolidada para lidar com esses casos de dependência. Torna-se necessária a compreensão do que está por trás dessa dependência comportamental, bem como a identificação da necessidade dessa criança ou desse jovem que não está sendo atendida no mundo presencial. Esse olhar sensível, tanto dos educadores parentais quanto dos profissionais da educação, é indispensável para se pensar a saúde mental desses estudantes e para que sejam acionados, caso necessário, outros profissionais, como psicólogos.

Como a escola, por vezes, ignora as redes sociais, e as famílias, em muitos casos, não conseguem acompanhar de perto as ações dos jovens e das crianças na internet, a exposição, o compartilhamento de imagens constrangedoras e o cyberbullying acabam sendo práticas rotineiras nessas comunidades virtuais. Esse processo atinge, direta ou indiretamente, as relações escolares.

Evidenciamos ainda uma fala de um professor da rede pública do Distrito Federal que afirma que "julgamentos, classificações e comparações da vida do outro [podem] estimular a violência e a depreciação dos indivíduos". O educador também sinaliza que o mau uso das redes sociais contribui para rótulos e cyberbullying.

É fundamental que os educandos sejam formados para refletirem, dentro dessa educação digital e midiática, sobre os conceitos de domínio público e de domínio privado, como um primeiro passo para diminuir o índice de exposições e compartilhamentos de imagens constrangedoras.

Outra problematização levantada nessa discussão é a banalização do uso de imagens e notícias. Há excesso de informação e, por vezes, não há aprofundamento nem análise de toda essa demanda. 
cada vez está melhor informado, porém, com essa obsessão pela informação e pelo saber (mas saber não no sentido de "sabedoria", mas no sentido de "estar informado"), o que consegue é que nada lhe aconteça. (BONDÍA, 2002, p. 21, 22).

Sem reflexões contínuas sobre essa grande demanda de estímulos icônicos, dificilmente os educadores poderão auxiliar na vivência mais respeitosa nos ambientes virtuais. Assim, para transformar essa realidade, é importante que as escolas desenvolvam projetos de educação digital que envolvam toda a comunidade escolar.

\subsubsection{Em sua escola há algum projeto de educação digital? Se sim, qual?}

O intuito dessa pergunta é verificar se o profissional questionado conhece ou desenvolve algum projeto de educação digital dentro de sua escola e, em caso positivo, saber qual projeto estaria sendo aplicado e desenvolvido. Durante a análise, percebemos que as respostas positivas e negativas ficaram, de certa forma, equilibradas. No entanto, as respostas afirmativas ainda predominaram, com $58 \%$ dos respondentes. Já os outros $42 \%$ afirmam a inexistência de tais projetos em suas instituições ou o desconhecimento de sua existência.

A maior parte dos participantes que responderam negativamente atribuíram desconhecimento da existência de projetos dessa natureza em sua escola, independentemente do tipo de instituição (pública/privada). Outros informaram que o assunto é tratado com frequência a partir de uma perspectiva multidisciplinar e transversal, ou seja, cada professor, dentro de sua disciplina, aborda o assunto de maneira individualizada, fora de um contexto organizado e temporal como o de um projeto. Houve um dos respondentes que nos chamou a atenção por mencionar que alguns gestores imaginam a educação digital como sendo suficientemente contemplada pelo simples ato de "ensinar os alunos a mexerem no computador".

Por outro lado, a maior parte dos respondentes que confirmaram a existência de projetos apresentaram respostas divergentes ou difusas no tocante ao conhecimento sobre o tema educação digital. Muitos relataram que a promoção do tema é contemplada com simples utilização de laboratório de informática; outros informaram a utilização de ferramentas como Google ClassRoom, aplicativos de ensino, robótica, jogos ou alguma plataforma de estudo online. Porém, poucos apresentaram projetos reais como a criação de rádio online, projeto Antibullying, Internet com ética e jornal online.

A análise desse quesito, demonstrada nesse recorte de respondentes, apresenta alta similaridade com a realidade. Ao realizarem-se buscas nas literaturas especializadas, observase, em muitas escolas do país, a ausência de projetos para tratamento, desenvolvimento e promoção da educação digital; em contrapartida, existem iniciativas espalhadas - nem sempre em forma de projetos - que realizam estudos com os diversos temas já apresentados nas respostas, como rádio e jornal online, uso de plataformas virtuais, apps, jogos, robótica e, também, a análise crítica de notícias para combate às fake news, todos relatados em iniciativas como as de Garcia (2008), Simão (2018) e Oliveira e Rodrigues (2018).

Talvez, o motivo para ainda não detectarmos uma prática de educação digital ou midiática generalizada nas instituições seja porque a BNCC apresenta e indica a importância do conhecimento sobre tecnologias digitais como Competências Gerais da Educação Básica em sua versão mais recente, de 2018. Reiteramos o que o documento requer como competência: 
Compreender, utilizar e criar tecnologias digitais de informação e comunicação de forma crítica, significativa, reflexiva e ética nas diversas práticas sociais (incluindo as escolares) para se comunicar, acessar e disseminar informações, produzir conhecimentos, resolver problemas e exercer protagonismo e autoria na vida pessoal e coletiva. (BRASIL, 2018, p. 9).

Imagina-se que, a partir da importância da educação midiática apresentada como diretriz na BNCC, as instituições de ensino possam aprimorar suas práticas no tocante à educação midiática e digital e construírem estratégias para o desenvolvimento do tema nas atividades pedagógicas, de maneira permanente e sistemática.

\subsubsection{Você acredita que as redes sociais poderiam ser ferramentas para o desenvolvimento de alunos? Justifique.}

Houve uma quantidade surpreendentemente alta de respostas positivas a essa pergunta, sendo um total de $91 \%$ dos participantes. 3\% apresentaram respostas indefinidas e $6 \%$ responderam negativamente.

Para os participantes que não consideram a rede social como ferramenta para desenvolvimento dos estudantes, foi possível perceber, nas respostas, o receio de "haver distração" dos alunos e, consequentemente, desvio da real intenção do processo de ensinoaprendizagem. Um respondente enfatiza que a rede social, na verdade, "é ferramenta de entretenimento" e "não é ferramenta de pesquisa confiável". Vale pontuar que esses 6\% são respondentes com idades que variam entre 47 e 54 anos, ou seja, são os sujeitos de pesquisa mais velhos entre a amostra.

Algumas respostas indefinidas trouxeram a necessidade de um uso controlado das redes sociais por meio de algum acompanhamento e/ou direcionamento dos estudantes para realização das tarefas nesses ambientes. Além disso, alguns respondentes consideraram vital a verificação, com cuidado, dos conteúdos relacionados à devida faixa etária e, também, a percepção de que nem todas as redes sociais podem ser satisfatoriamente utilizadas.

Mais de $90 \%$ dos profissionais de ensino pesquisados acreditam que as redes sociais são ferramentas de desenvolvimento dos estudantes. Esses respondentes apontam diversas vantagens e benefícios de seu uso. A fim de facilitar a análise, o conjunto dos ganhos com a utilização das redes sociais foi organizado em sete categorias:

a) atualização e rapidez das informações;

b) criação de redes, compartilhamento e divulgação;

c) uso guiado e projetos;

d) interação;

e) pesquisas, estudos, aprendizagem e criticidade;

f) cautela e reflexão;

g) ampliação dos conteúdos ministrados em sala de aula.

Na primeira categoria, os participantes confirmaram que o uso das redes sociais facilita a obtenção rápida e atualizada de conteúdos por parte dos alunos. De certo modo, no contexto atual, raramente o estudante não tem ciência de alguma notícia que tenha sido amplamente divulgada. Esse envolvimento faz com que, muitas vezes, a própria rede social seja a fonte de notícias para o estudante, ao invés das mídias tradicionais em papel, como jornais e revistas. 
A segunda categoria traz o aspecto benéfico da rede social como forma de possibilidades de compartilhamentos, divulgações e esquemas de redes de qualquer tipo. Um respondente concorda que esse item é muito importante para fomentar solidariedade e ações sociais, como na promoção da "corrente do bem" e da vakinha online, por exemplo; ademais, alguns profissionais utilizam as redes para divulgação de materiais ou conteúdos interessantes, sendo uma forma de troca de informações; há, ainda, espaço para realização de jogos online, postagem de vídeos de conscientização e competições de conhecimento. Esses modernos exercícios são considerados grandes aliados pedagógicos, se usados com cuidado, e revelam complementação ao ensino tradicional.

Uma parcela dos profissionais concorda com o uso das redes sociais desde que seja mediada, acompanhada e supervisionada por um professor. Um participante assevera que o usufruto das possibilidades dessas tecnologias deveria ser organizado por meio de projetos pedagógicos; dessa forma, há um benefício maior para os estudantes, para os pais, para a escola e para toda a comunidade acadêmica, tendo em vista a oportunidade de a instituição receber recursos externos e fomentar a pesquisa e a extensão. A adesão dos discentes é ampliada com a união de todos os docentes na utilização das tecnologias educacionais e no uso de apps como Google Classroom, Youtube, bem como na utilização de fóruns nas comunidades, como Reddit, que, além de permitir a troca de experiências, permite um desenvolvimento da educação digital de forma multidisciplinar.

Alguns respondentes lembram da cultura digital no tocante a sua facilidade para a interação. A socialização online facilita o entrosamento de estudantes (inclusive os ditos tímidos) na medida em que esses interagem com a plataforma compartilhando conteúdos, curtindo e comentando nos posts dos colegas. Além disso, o aluno é encarado como protagonista do processo de ensino-aprendizagem. Nesse sentido, Santaella (2003) endossa a afirmação e mostra que a capacidade de interação no mundo online supera, muitas vezes, a da realidade, devido à tamanha organização e abrangência das pessoas na internet.

A pesquisa, tão importante para a construção do conhecimento (DEMO, 1982), pode ser facilmente realizada nessas plataformas. Uma das vantagens do uso das redes sociais, quando acompanhada pelos docentes, é abrir espaços para a reflexão dos assuntos, apoiar as buscas, desenvolver o senso crítico e a aprendizagem propriamente dita. Como há vários canais para discussão, criação de grupos de estudos e apresentação de novas ideias, o ambiente é propício para promover atitudes e pensamentos críticos, bem como características fundamentais de uma atitude filosófica, conforme M. Chaui (2000, p. 9):

A primeira característica da atitude filosófica é negativa, isto é, um dizer não ao senso comum, aos pré-conceitos, aos pré-juízos, aos fatos e às idéias [sic] da experiência cotidiana, ao que "todo mundo diz e pensa", ao estabelecido. A segunda característica da atitude filosófica é positiva, isto é, uma interrogação sobre o que são as coisas, as idéias [sic], os fatos, as situações, os comportamentos, os valores, nós mesmos. É também uma interrogação sobre o porquê disso tudo e de nós, e uma interrogação sobre como tudo isso é assim e não de outra maneira. O que é? Por que é? Como é? Essas são as indagações fundamentais da atitude filosófica. A face negativa e a face positiva da atitude filosófica constituem o que chamamos de atitude crítica e pensamento crítico.

A partir dessa atitude filosófica, espera-se conscientizar os estudantes quanto à necessidade de análise da veracidade das informações, assim como de suas origens e de seus conteúdos, práticas fundamentais ao combate às fake news. 
Em relação aos limites na utilização das redes sociais, alguns respondentes reafirmam a necessidade de cautela no uso pedagógico dessas redes, pois, primeiramente, é preciso planejamento, controle e definição clara dos objetivos a serem atingidos com o seu uso. $\mathrm{O}$ aprimoramento da capacidade de reflexão dos conteúdos é algo muito importante e condizente com esse processo, visto que há grande tendência das ações ocorrerem de forma automática. Uma das respostas dessa categoria foi bastante contundente: "é preciso que o aluno seja orientado a sintetizar, a partir da análise crítica e reflexão, a totalidade da informação que recebe."

Por fim, a última categoria apresenta a ampliação e o enriquecimento dos conteúdos da sala de aula que as redes podem suscitar. A partir de sua utilização, o professor adentra no inegável cotidiano tecnológico do estudante e consegue estimulá-lo à aderência do conteúdo proposto. $\mathrm{O}$ engajamento dos estudantes - às vezes tão difícil de se obter durante a aula tradicional em sala - pode ser facilmente obtido por meio de uma atividade online, desde que esta seja programada, controlada, acompanhada e que traga aos estudantes a oportunidade de reflexão, análise crítica e protagonismo.

\subsubsection{Discussão de resultados}

O levantamento realizado, apesar de apresentar um olhar mais específico e regional, pode contribuir para a pesquisa em educação, pois indica a escassez de projetos de educação digital nas escolas públicas e privadas que foram avaliadas.

Entretanto, apesar dessa escassez, existe uma clara necessidade da implementação desses aparatos, considerando-se que a maior parte dos educadores entrevistados consegue observar uma relação entre os conflitos escolares dos educandos e as redes sociais.

Além disso, os desafios advindos das redes sociais, descritos pelos educadores, são de extrema relevância e podem representar questões comuns a outras instituições brasileiras, o que fomenta a necessidade de mais pesquisas e desenvolvimento de projetos nessa área da educação.

Uma outra observação verificada, revelada na pesquisa, foi a constatação de que, para 91\% dos participantes, as redes sociais na internet são ferramentas válidas que contribuem para o desenvolvimento dos educandos. Por outro lado, a partir de um cruzamento de dados, foi desvendado que os respondentes que não consideram as redes sociais como possíveis ferramentas educacionais são pessoas que possuem uma idade maior em relação ao restante dos respondentes. Talvez esse pensamento decorra de uma certa resistência que esse grupos tenham em relação ao aspecto formativo das redes sociais, por não terem, porventura, acompanhado a criação e o desenvolvimento dessas tecnologias ao longo do tempo.

Reiteramos que, apesar de a pesquisa representar algumas especificidades de determinadas comunidades escolares do DF, ela pode servir como um parâmetro para que a pesquisa em educação reflita mais a respeito da relação entre o processo de ensinoaprendizagem e as redes sociais, fomentando a necessidade de uma educação digital na formação tanto dos educandos quanto dos educadores.

\section{Considerações finais}

A presente investigação não se esgota neste artigo. Enquanto educadores, há muito o que debatermos e refletirmos a respeito da prática de uma educação digital que seja eficiente e eficaz. 
É certo que não podemos desvencilhar a prática educacional do contexto em que o sujeito encontra-se. Educação tem tudo a ver com cultura, processos interativos, aprendizagem social, comunicação, afetividade, entre tantos outros aspectos.

O século XXI caracteriza-se pela era digital, a qual, conforme exposto no artigo, influenciou todas as formas de relações humanas de maneira sistêmica, inclusive "como se aprende", o que é definido como "interessante", as formas eficazes de transmissão de informações e de construção de conhecimento, a relação do professor com o aluno, entre outros fatores. A tecnologia, enquanto avanço e desenvolvimento, certamente trouxe consigo fortes dilemas e desafios à prática educacional.

É fato que as instituições educacionais sempre tiveram demandas no processo de ensinoaprendizagem. No entanto, é fundamental que, em nosso contexto e com base nas competências a serem desenvolvidas na formação dos educandos, sugeridas pela BNCC, examinemos esse processo de maneira a relacioná-lo às necessidades atuais de uma educação para o uso das redes sociais, de maneira que formemos indivíduos "preparados" para serem éticos no uso das redes, utilizando-as da melhor forma não somente no ambiente escolar, mas na vida.

\section{Referências}

ABREU, C. N.; KARAM, R. G.; GÓES, D. S.; SPRITZER, D. T.. Dependência de Internet e de jogos eletrônicos: uma revisão. Rev. Bras. Psiquiátrica, v.. 30, n. 2, p. 156-167, São Paulo, jun. 2008.

BONDÍA, Jorge Larrosa. Notas sobre a experiência e o saber de experiência. Revista Brasileira da Educação, n.. 19, jan./fev./mar./abr., Rio de Janeiro, ANPED, 2002.

BRASIL. Base Nacional Comum Curricular: Ensino Médio. Brasília: MEC/Secretaria de Educação Básica, 2018.

BUCKINGHAM, David. Cultura Digital, Educação Midiática e o Lugar da Escolarização. Educ. Real., Porto Alegre, v. 35, n. 3, p. 37-58, set./dez. 2010. Disponível em: http://www.ufrgs.br/edu_realidade/. Acesso em: 14 jun. 2019.

CHAUI, M. Convite à Filosofia. São Paulo: Ática, 2000.

DEMO, P. Pesquisa participante: mito e realidade. Brasília: INEP, 1982.

FIDALGO, Adriano. Educação Digital. Aspectos Conceituais. Disponível em: https://administradores.com.br/artigos/educacao-digital-aspectos-conceituais. Acesso em: 14 jun. 2019.

FORTIM, I.; ARAUJO, C. A. (2013). Aspectos Psicológicos do uso patológico de Internet. Boletim da Academia Paulista de Psicologia, v. 33, n. 85, p. 292-311, São Paulo, dez. 2013.

FUNKS, Hugo et al. Novas estratégias de Avaliação On-line: aplicações e implicações em curso totalmente a distância através do ambiente AulaNet. In: SANTOS, Edméa; SILVA, 
Marcos. Avaliação da Aprendizagem em Educação Online. São Paulo: Editora Loyola 2006.

GARCIA, L. A. R. Uma proposta de letramento midiático para os professores do Ensino Médio de Cascavel (PR). Seminário de $16^{\circ} \mathrm{COLE}$ vinculado: 05. Maringá: UEM/Mestrado em Letras, Maringá (PR). 2008. p. 1-10.

GODINHO, Francisco Alexandre Ferreira Biscaia. Uma nova abordagem para a formação de engenharia de reabilitação em Portugal. Vila Real, 2010. Tese (Doutorado) Universidade de Trás-os-Montes e Alto Douro, Engenharia Electrotécnica e de Computadores.

LANDRY, Normand; BASQUE, Joelle. A educação para as mídias: Contribuições, práticas e perspectivas de pesquisa em ciência da comunicação. Trad. Florence Dravet. Revista Esferas, n. 13, 2018.

MASIERO, Paulo Cesar. Ética em Computação. Edusp: São Paulo. 2000.

OLIVEIRA, F. C. R. M.; RODRIGUES, R. T. P. Legere et interpretari: letramentos midiáticos como metodologia de aprendizagem. Revista Eletrônica de Comunicação, Informação \& Inovação em Saúde, p. 1-11, Rio de Janeiro, jan. 2018.

RECUERO, Raquel. Redes Sociais na Internet. Porto Alegre: Sulina, 2009.

SANTAELLA, Lucia. Culturas e artes do pós-humano: da cultura das mídias à cibercultura. São Paulo: Paulus, 2003.

SIMÃO, Renan Borges. Como é o letramento midiático fora da Língua Portuguesa? Disponível em: https://novaescola.org.br/conteudo/12550/como-e-o-letramento-midiaticofora-da-lingua-portuguesa. Acesso em: 13 maio 2019.

TURCHI, Sandra R. Estratégias de Marketing Digital e E-commerce. 2 ed.. São Paulo: Atlas, 2019.

YASAWA, Giane da S. F.; FRANÇA, Eliacir Neves. Redes sociais na escola: Uso consciente e ético. In: Os Desafios da escola pública paranaense na perspectiva do professor. Cadernos PDE, v. 2, Universidade Estadual de Londrina, 2013.

Recebido em setembro de 2019.

Aprovado em maio de 2020. 